\title{
Phenotypic diversity of brain MRI patterns in mitochondrial aminoacyl-tRNA synthetase mutations
}

Charles-Joris Roux, ${ }^{1}$ Giulia Barcia, ${ }^{2}$ Manuel Schiff, ${ }^{2}$ Marie Sissler, ${ }^{4}$ Raphaël Levy, ${ }^{1}$ Volodia Dangouloff-Ros, ${ }^{1}$ Isabelle Desguerre, ${ }^{3}$ Shiimon Edvardson, ${ }^{5}$ Orli Elpeleg, ${ }^{5}$ Agnès Rötig, ${ }^{6}$ Arnold Munnich, ${ }^{2,6}$ Nathalie Boddaert ${ }^{1,6}$

\section{Author affiliations}

${ }^{1}$ Department of Paediatric Radiology, Hôpital Necker-Enfants Malades, Paris, France

${ }^{2}$ Department of Genetics, Hospital Necker-Enfants Malades, Paris, France

${ }^{3}$ Department of Neurology and Metabolism, Hôpital Necker-Enfants Malades, Paris, France

${ }^{4}$ Institut Européen de Chimie et Biologie, INSERM U1212, CNRS UMR 5320, University of Bordeaux, Pessac, France

${ }^{5}$ Department of Genetics, Hadassah University Hospital, Jerusalem, Israel

${ }^{6}$ Institut Imagine, INSERM UMR 1163, Paris, France

\section{Correspondence to}

Dr Charles-Joris Roux, Department of Paediatric Radiology, Hôpital Necker-Enfants Malades, 75015 Paris, France; charles-joris.roux@aphp.fr 


\section{Abstract}

Background and purpose: Mitochondrial aminoacyl-tRNA synthetases-encoded by ARS2 genes-are evolutionarily conserved enzymes that catalyse the attachment of amino acids to their cognate tRNAs, ensuring the accuracy of the mitochondrial translation process. ARS2 gene mutations are associated with a wide range of clinical presentations affecting the CNS.

Methods: Two senior neuroradiologists analysed brain MRI of 25 patients (age range: $3 \mathrm{~d}-$ 25 yrs.; 11 males; 14 females) with biallelic pathogenic variants of 11 ARS2 genes in a retrospective study conducted between 2002 and 2019.

Results: Though several combinations of brain MRI anomalies were highly suggestive of specific aetiologies (DARS2, EARS2, AARS2 and RARS2 mutations), our study detected no MRI pattern common to all patients. Stroke-like lesions were associated with pathogenic SARS2 and FARS2 variants. We also report early onset cerebellar atrophy and calcifications in AARS2 mutations, early white matter involvement in RARS2 mutations, and absent involvement of thalami in EARS2 mutations. Finally, our findings show that normal brain MRI results do not exclude the presence of ARS2 mutations: 5 patients with normal MRI images were carriers of pathogenic IARS2, YARS2, and FARS2 variants.

Conclusion: Our study extends the spectrum of brain MRI anomalies associated with pathogenic ARS2 variants and suggests ARS2 mutations are largely underdiagnosed

\section{Introduction}

Aminoacyl-tRNA synthetases (ARS) are evolutionarily conserved enzymes that catalyze the binding of amino acids to their corresponding tRNAs. As such, they contribute to the accuracy of the translation process. Two separate sets of cellular ARSs are required because translation takes place in two distinct compartments: the cytosol and the mitochondria. There are 18 ARSs solely active in the cytosol, comprising the ARS1 group; 17 solely active in the mitochondria, comprising the ARS2 group; and 2 bifunctional ARSs, active in both compartments $[1,2]$. Both cytosolic and mitochondrial ARSs are encoded by nuclear genes. Mitochondrial translation disorders result in isolated or multiple deficiencies of the ATPproducing oxidative phosphorylation system. They include mutations of nuclear ARS2 genes, which have emerged as a new group of mitochondrial diseases inconsistently impairing oxidative phosphorylation and ATP production $[3,4]$. While one might expect mitochondrial 
ARS mutations to predominantly affect mitochondrial protein synthesis, they actually result in a striking variety of clinical phenotypes involving a wide range of tissues with high energy needs [4,5]. Reviewing a series of 25 patients carrying biallelic pathogenic ARS2 variants, here we consider the phenotypic diversity of brain MRI anomalies associated with this emergent group of

mitochondrial diseases.

\section{Methods}

We have followed the STROBE guidelines for this retrospective observational study. Local Institutional Review Board authorization was granted and the requirement for written informed consent was waived.

\subsection{Patients}

A total of 25 unreported patients (11 males, 14 females; age range: 3 days-25 years old) carrying biallelic pathogenic variants of 11 ARS2 genes-AARS2 ([number of patients:] 2), DARS2 (2), EARS2 (4), FARS2 (4), KARS (1), IARS2 (4), NARS2 (1), RARS2 (4), SARS2 (1), WARS2 (1), and YARS2 (1)-were included in this single-centre retrospective study conducted between 2002 and 2019.

\subsection{Procedures}

Routine MRI was performed on a 1.5or 3-T MRI scanner (GE Healthcare, Milwaukee, USA). All children $<5$ years old received standard premedication (pentobarbital, $0.2 \mathrm{~mL} / \mathrm{kg} ; 5$ $\mathrm{mg} / \mathrm{kg}$ ) to avoid head movement during MRI acquisition. MRI protocols included 3D T1weighted, axial T2or T2-FLAIR-weighted, diffusion-weighted, and occasionally, MRS (echo time: $144 \mathrm{~ms}$ ) and arterial spin labelling (ASL) perfusion imaging. Two senior paediatric neuroradiologists (authors CJR and NB, respectively 8 years and 25 years of experience) blinded to genetic data independently analysed the brain MRI, considering the aspect and signal intensity of the basal ganglia (putamen, pallidum, and caudate),thalamus, corpus callosum, corticospinal tract, brain stem (especially the periaqueductal region), cerebellum, dentate nuclei, cerebral cortex, white matter, and stroke-like lesions, as well as MRS evidence of a lactate peak (1.33 ppm). 


\section{Results}

Clinical presentation, pathogenic ARS2 gene variants, and neuroimaging observations for the patients are given in Table 1. No brain MRI pattern common to all patients emerged from our study. Anomalies common to multiple mutant genes included leukodystrophy (9 patients: 1 AARS2, 2 DARS2, 3 EARS2, 2 RARS2, and 1 WARS2), intramyelinic vacuolization (3 patients: 2 DARS2 and 1 AARS2), abnormal basal ganglia (9 patients: 2 AARS2, 3 EARS2, 2 FARS2, 1 IARS2 and 1 RARS2), major cortical atrophy (8 patients: 2 FARS2, 1 KARS, 1 NARS2, 3 RARS2, and 1 WARS2), MRS evidence of a lactate peak (9/13 patients, 2 AARS2, 1 DARS2, 1 FARS2, 1 IARS2, 1 KARS, 1 NARS2, 2 RARS2), (Fig. 1). Interestingly, two patients presented an acute neurological deficit, with seizures, and cortical hyperintensities in diffusion-weighted and T2 sequences, with hyper perfusion in ASL; one in the occipital lobe (1 FARS2), the other in the cerebellum (1 SARS 2, Fig.1 (S\|U). Stroke-like lesions are known to be associated with mitochondrial DNA mutations and inborn errors of coenzyme Q10 synthesis but had never been previously reported in association with pathogenic ARS2 variants.

\subsection{Specific MR imaging pattern}

Though, as just described, some radiological signs were associated with numerous mutant genes, we identified several combinations of brain anomalies that strongly suggested specific aetiologies (Table 2). For instance, the 2 patients with pathogenic DARS2 variants displayed the typical pattern of leukoencephalopathy with brain stem and spinal cord involvement and lactate elevation LBSL) [6-10]. This includes diffuse symmetric inhomogeneous lesions, with preponderant supratentorial, periventricular and subcortical cerebellar lesions, sparing $U$ fibres. The lateral corticospinal tracts, medullary pyramids, posterior limb of the internal capsule, spinal cord dorsal columns, medial lemniscus, intraparenchymal trigeminal pathways, and cerebellar peduncles were also involved, as is typical. Similarly, leukodystrophy sparing the periventricular white matter was highly suggestive, if not specific to, EARS2 mutations (in 3 of the 4 patients with pathogenic EARS2 variants) $[8,9,11]$; leukodystrophy with vacuolization in diffusion sequence was suggestive of an AARS2 mutation especially if cerebellar atrophy was present (in 1 of the 2 patients with pathogenic AARS2 variants) [8,12-14]; and pontocerebellar hypoplasia (PCH6) with MRS evidence of a lactate peak was highly suggestive of an RARS2 mutation (in all 2 patients with pathogenic RARS2 variants) $[9,15,16]$. 


\subsection{Broadening the spectrum}

Our study extended the spectrum of brain MRI anomalies in pathogenic ARS2 genes. In 2 of the 4 patients with pathogenic RARS2 variants and typical pontocerebellar hypoplasia, early white matter involvement $(<2 \mathrm{mo})$ preceded cortical atrophy, possibly triggering further global supratentorial involution. Also, a 4-y-old boy carrying biallelic AARS2 mutations had major cerebellar atrophy with calcifications of basal ganglia but no leukodystrophy, a profile hitherto observed in the third decade of life $[17,18]$. Similarly, bilateral anomalies of the thalami, regarded as consistent features in biallelic EARS2 mutations, were absent in 3 of the 4 pathogenic EARS2 cases, otherwise presenting with the previously reported symmetrical leukodystrophy sparing the periventricular region. Along the same lines, while pathogenic IARS2 variants reportedly cause Leigh syndrome with abnormal basal ganglia and high cerebrospinal fluid lactate levels [19], brain MRI images were apparently normal for 3 of the 4 mutants IARS2 patients.

\subsection{New findings}

We also report here what we believe to be the first brain MRI imaging for pathogenic variants of YARS2 (1 case: unremarkable MRI) and add to the very limited knowledge about neuroimaging of pathogenic variants of SARS2 (1 case: cerebellar stroke-like lesion), WARS2 (1 case: leukodystrophy) [20] and NARS2 (1 case: global brain atrophy) [21,22]. Our study also points to the involvement of the dentate nuclei in pathogenic FARS2 variants ( 3 of the 4 cases) [23-25]. Finally, the apparent absence of brain MRI anomalies in 5 (3 IARS2, 1 YARS2, and 1 FARS2) of the 25 patients suggests that normal brain MRI images do not exclude the diagnosis of ARS2 mutations in mitochondrial diseases.

\section{Discussion}

No common MRI pattern was detected for our series of 25 patients with biallelic pathogenic variants in 11 ARS2 genes. Nevertheless, several combinations of brain anomalies strongly suggested specific aetiologies: leukodystrophy sparing periventricular white matter for EARS2 mutations, cerebellar atrophy with asymmetric leukodystrophy and vacuolization in diffusion sequences for AARS2 mutations, pontocerebellar hypoplasia with MRS evidence of 
a lactate peak for RARS2 mutations, and leukoencephalopathy with brain stem and spinal cord involvement and lactate elevation for DARS2 mutations.

Our study also extends the range of brain MRI anomalies and docu-ments the natural history of pathogenic ARS2 variants: stroke-like lesions were associated with SARS2 and FARS2 mutations, leukodystrophy preceded global brain atrophy in RARS2 mutations, major cerebellar atrophy with basal ganglia involvement and subcortical calcifications were seen in AARS2 mutations, and thalamic involvement was an in-consistent feature in EARS2 mutations. The limited number of MRI per patient and per gene hampers commenting on evolution of MRI anomalies. It is worth noting remembering that progressive cortical and cerebellar atrophy have been reported in RARS2 mutations [15]. Moreover, because five patients had apparently normal MRI images, our study shows the latter does not exclude the presence of ARS2 mutations. As not only neuroimaging but also metabolic workups and respiratory chain enzyme activity can be unremarkable for pathogenic ARS2 variants, they are likely to be greatly underdiagnosed. To avoid mis-diagnoses, exhaustive neuroimaging investigations of mitochondrial diseases should be repeated when appropriate and should always employ the following MRI sequences: T2 and FLAIR for analysis of the white matter, diffusion-weighted sequences for detection of vacuolization (DARS2 and AARS2 mutations), MRS for detection of lactate peaks in affected and non-affected areas, and 3D T1 for analysis of the cerebellum (AARS2 and RARS2) as well as brain perfusion (ASL) to detect stroke-like or acute Leigh syndrome when feasible. The diversity of brain imaging patterns in ARS2 mutations reported here and in the literature reflects the wide range of clinical presentations associated with these pathogenic variants. It suggests that disease linked to ARS2 mutations is not caused by a single molecular mechanism. Two main hypotheses have been advanced $[4,8,26]$. The first proposes that developmental differences in energy requirements between tissues render some mitochondrial translation defects more deleterious in some and lower the threshold at which a reduction in ATP production is damaging. The second posits that ARS2 enzymes may have hitherto unknown functions other than canonical tRNA aminoacylation. While this has held true for cytosolic ARS $[27,28]$, reports of noncanonical roles for ARS2 enzymes are only starting to emerge. Indeed, in rat, WARS2 has been shown to have proangiogenic functions [29]. More recently, three mitochondrial ARS enzymes (DARS2, RARS2 and KARS) have been shown to occupy distinct sub mitochondrial regions, suggesting additional properties, biological functions, and clinical 
relevance [30]. Assuming mitochondrial translation is integrated within cell metabolism and acts as an environmental sensor, it is conceivable that other-and possibly manyconnections between ARS2 and cellular homeostasis may exist and account for the extensive clinical heterogeneity of these recently identified conditions.

\section{Conclusion}

Although no common pattern emerged from the study, it extends the spectrum of brain MRI anomalies associated with ARS2 mutations - especially with stroke-like lesions reported for the first time in pathogenic ARS2 variants - and suggests that ARS2 variants are largely underdiagnosed.

\section{Funding}

Nothing to report.

\section{Competing interests}

No conflict of interest.

\section{Data availability statement}

All data relevant to the study are included in the article or uploaded as supplementary information.

\section{Acknowledgements}

We thank Jason MILLER for reviewing the manuscript.

\section{References}

[1] M. Ibba, D. Soll, Aminoacyl-tRNA synthesis, Annu. Rev. Biochem. 69 (2000) 617-650, https://doi.org/10.1146/annurev.biochem.69.1.617.

[2] A. Antonellis, E.D. Green, The role of aminoacyl-tRNA synthetases in genetic diseases, Annu. Rev. Genomics Hum. Genet. 9 (2008) 87-107, https://doi.org/10.

1146/annurev.genom.9.081307.164204.

[3] S. Konovalova, H. Tyynismaa, Mitochondrial aminoacyl-tRNA synthetases in human disease, Mol. Genet. Metab. 108 (2013) 206-211, https://doi.org/10.1016/j.ymgme. 2013.01.010. 
[4] L.E. González-Serrano, J.W. Chihade, M. Sissler, When a common biological role does not imply common disease outcomes: disparate pathology linked to human mitochondrial aminoacyl-tRNA synthetases, J. Biol. Chem. 294 (2019) 5309-5320, https://doi.org/10.1074/jbc.REV118.002953.

[5] R. Meyer-Schuman, A. Antonellis, Emerging mechanisms of aminoacyl-tRNA synthetase mutations in recessive and dominant human disease, Hum. Mol. Genet. 26 (2017) R114-R127, https://doi.org/10.1093/hmg/ddx231.

[6] M.E. Steenweg, P.J.W. Pouwels, N.I. Wolf, W.N. van Wieringen, F. Barkhof, M.S. van der Knaap, Leucoencephalopathy with brainstem and spinal cord involvement and high lactate: quantitative magnetic resonance imaging, Brain 134 (2011) 3333-3341, https://doi.org/10.1093/brain/awr254.

[7] M.S. van der Knaap, M. Bugiani, Leukodystrophies: a proposed classification system based on pathological changes and pathogenetic mechanisms, Acta Neuropathol. 134 (2017) 351-382, https://doi.org/10.1007/s00401-017-1739-1.

[8] A.S. Fine, C.L. Nemeth, M.L. Kaufman, A. Fatemi, Mitochondrial aminoacyl-tRNA synthetase disorders: an emerging group of developmental disorders of myelination, J. Neurodev. Disord. 11 (2019) 29, https://doi.org/10.1186/s11689-019-9292-y. [9] A. Al Balushi, D. Matviychuk, R. Jobling, G.S. Salomons, S. Blaser, S. MercimekAndrews, Phenotypes and genotypes of mitochondrial aminoacyl-tRNA synthetase deficiencies from a single neurometabolic clinic, JIMD Rep. 51 (2020) 3-10, https://doi.org/10.1002/jmd2.12079.

[10] G.C. Scheper, T. van der Klok, R.J. van Andel, C.G.M. van Berkel, M. Sissler, J. Smet, T.I. Muravina, S.V. Serkov, G. Uziel, M. Bugiani, R. Schiffmann, I. Krägeloh-Mann, J.A.M. Smeitink, C. Florentz, R. Van Coster, J.C. Pronk, M.S. van der Knaap, Mitochondrial aspartyl-tRNA synthetase deficiency causes leukoencephalopathy with brain stem and spinal cord involvement and lactate elevation, Nat. Genet. 39 (2007) 534-539, https://doi.org/10.1038/ng2013.

[11] R. Biancheri, E. Lamantea, M. Severino, D. Diodato, M. Pedemonte, D. Cassandrini, A. Ploederl, F. Trucco, C. Fiorillo, C. Minetti, F.M. Santorelli, M. Zeviani, C. Bruno, Expanding the clinical and magnetic resonance spectrum of leukoencephalopathy with Thalamus and Brainstem Involvement and High Lactate (LTBL) in a patient harboring a novel EARS2 mutation, in: J. Zschocke, M. Baumgartner, E. Morava, M. 
Patterson, S. Rahman, V. Peters (Eds.), JIMD Reports, Vol. 23, Springer Berlin Heidelberg, Berlin, Heidelberg 2015, pp. 85-89, https://doi.org/10.1007/8904_2015_434. [12] R. Lakshmanan, M.E. Adams, D.S. Lynch, J.A. Kinsella, R. Phadke, J.M. Schott, E. Murphy, J.D. Rohrer, J. Chataway, H. Houlden, N.C. Fox, I. Davagnanam, Redefining the phenotype of ALSP and AARS2 mutation-related leukodystrophy, Neurol Genet. 3 (2017), e135, https://doi.org/10.1212/NXG.0000000000000135. [13] D.S. Lynch, W.J. Zhang, R. Lakshmanan, J.A. Kinsella, G.A. Uzun, M. Karbay, Z. Tüfekçioglu, H. Hanagasi, G. Burke, N. Foulds, S.R. Hammans, A. Bhattacharjee, H. Wilson, M. Adams, M. Walker, J.A.R. Nicoll, J. Chataway, N. Fox, I. Davagnanam, R. Phadke, H. Houlden, Analysis of mutations in AARS2 in a series of CSF1R-negative patients with adult-onset leukoencephalopathy with axonal spheroids and pigmented glia, JAMA Neurol. 73 (2016) 1433-1439, https://doi.org/10.1001/ jamaneurol.2016.2229.

[14] S. Srivastava, A. Butala, S. Mahida, J. Richter, W. Mu, A. Poretti, H. Vernon, J. VanGerpen, P.S. Atwal, E.H. Middlebrooks, D.S. Zee, S. Naidu, Expansion of the clinical spectrum associated with AARS2-related disorders, Am. J. Med. Genet. A 179 (2019) 1556-1564, https://doi.org/10.1002/ajmg.a.61188.

[15] J. Zhang, Z. Zhang, Y. Zhang, Y. Wu, Distinct magnetic resonance imaging features in a patient with novel RARS2 mutations: a case report and review of the literature, Exp. Ther. Med. 15 (2018) 1099-1104, https://doi.org/10.3892/etm.2017.5491. [16] D. Cassandrini, M.R. Cilio, M. Bianchi, M. Doimo, M. Balestri, A. Tessa, T. Rizza, G. Sartori, M.C. Meschini, C. Nesti, G. Tozzi, V. Petruzzella, F. Piemonte, L. Bisceglia, C. Bruno, C. Dionisi-Vici, A. D’Amico, F. Fattori, R. Carrozzo, L. Salviati, F.M. Santorelli, E. Bertini, Pontocerebellar hypoplasia type 6 caused by mutations in RARS2: definition of the clinical spectrum and molecular findings in five patients, J. Inherit. Metab. Dis. 36 (2013) 43-53, https://doi.org/10.1007/s10545-012-9487-9.

[17] X. Wang, Q. Wang, H. Tang, B. Chen, X. Dong, S. Niu, S. Li, Y. Shi, W. Shan, Z. Zhang, Novel alanyl-tRNA synthetase 2 pathogenic variants in leukodystrophies, Front. Neurol. 10 (2019) 1321, https://doi.org/10.3389/fneur.2019.01321.

[18] M.E. Kuo, A. Antonellis, V.G. Shakkottai, Alanyl-tRNA synthetase 2 (AARS2)-related ataxia without leukoencephalopathy, Cerebellum 19 (2020) 154-160, https://doi. org/10.1007/s12311-019-01080-y. 
[19] Y. Takezawa, H. Fujie, A. Kikuchi, T. Niihori, R. Funayama, M. Shirota, K. Nakayama, Y.

Aoki, M. Sasaki, S. Kure, Novel IARS2 mutations in Japanese siblings with CAGSSS, Leigh, and West syndrome, Brain Dev. 40 (2018) 934-938, https://doi.org/10. 1016/j.braindev.2018.06.010.

[20] M. Virdee, E. Swarnalingam, M. Kozenko, M. Tarnopolsky, K. Jones, Expanding the phenotype: neurodevelopmental disorder, mitochondrial, with abnormal movements and lactic acidosis, with or without seizures (NEMMLAS) due to WARS2 biallelic variants, encoding mitochondrial tryptophanyl-tRNA synthase, J. Child Neurol. 34 (2019) 778-781, https://doi.org/10.1177/0883073819854604. [21] L.H. Seaver, S. DeRoos, N.J. Andersen, B. Betz, J. Prokop, N. Lannen, R. Jordan, S. Rajasekaran, Lethal NARS2-related disorder associated with rapidly progressive intractable epilepsy and global brain atrophy, Pediatr. Neurol. 89 (2018) 26-30, https://doi.org/10.1016/j.pediatrneurol.2018.07.014.

[22] T. Mizuguchi, M. Nakashima, M. Kato, K. Yamada, T. Okanishi, N. Ekhilevitch, H. Mandel, A. Eran, M. Toyono, Y. Sawaishi, H. Motoi, M. Shiina, K. Ogata, S. Miyatake, N. Miyake, H. Saitsu, N. Matsumoto, PARS2 and NARS2 mutations in infantile-onset neurodegenerative disorder, J. Hum. Genet. 62 (2017) 525-529, https://doi.org/10.1038/jhg.2016.163.

[23] S.K. Sahai, R.E. Steiner, M.G. Au, J.M. Graham, N. Salamon, M. Ibba, T.M. Pierson, FARS2 mutations presenting with pure spastic paraplegia and lesions of the dentate nuclei, Ann. Clin. Transl. Neurol. 5 (2018) 1128-1133, https://doi.org/10.1002/acn3. 598.

[24] E. Vantroys, A. Larson, M. Friederich, K. Knight, M.A. Swanson, C.A. Powell, J. Smet, S. Vergult, B. De Paepe, S. Seneca, H. Roeyers, B. Menten, M. Minczuk, A. Vanlander, J. Van Hove, R. Van Coster, New insights into the phenotype of FARS2 deficiency, Mol. Genet. Metab. 122 (2017) 172-181, https://doi.org/10.1016/j.ymgme.2017. 10.004 .

[25] M. Almannai, J. Wang, H. Dai, A.W. El-Hattab, E.A. Faqeih, M.A. Saleh, A. Al Asmari, A.H. Alwadei, Y.I. Aljadhai, A. AlHashem, B. Tabarki, M.A. Lines, D.K. Grange, R. Benini, A.S. Alsaman, A. Mahmoud, P. Katsonis, O. Lichtarge, L.-J.C. Wong, FARS2 deficiency; new cases, review of clinical, biochemical, and molecular spectra, and variants interpretation based on structural, functional, and evolutionary significance, 
Mol. Genet. Metab. 125 (2018) 281-291, https://doi.org/10.1016/j.ymgme.2018.

07.014.

[26] M. Sissler, L.E. González-Serrano, E. Westhof, Recent advances in mitochondrial aminoacyl-tRNA synthetases and disease, Trends Mol. Med. 23 (2017) 693-708, https://doi.org/10.1016/j.molmed.2017.06.002.

[27] S. Kim, S. You, D. Hwang, Aminoacyl-tRNA synthetases and tumorigenesis: more than housekeeping, Nat. Rev. Cancer 11 (2011) 708-718, https://doi.org/10.1038/ nrc3124.

[28] M. Guo, P. Schimmel, Essential nontranslational functions of tRNA synthetases, Nat. Chem. Biol. 9 (2013) 145-153, https://doi.org/10.1038/nchembio.1158.

[29] M. Wang, P. Sips, E. Khin, M. Rotival, X. Sun, R. Ahmed, A.A. Widjaja, S. Schafer, P. Yusoff, P.K. Choksi, N.S.J. Ko, M.K. Singh, D. Epstein, Y. Guan, J. Houštěk, T. Mracek, H. Nuskova, B. Mikell, J. Tan, F. Pesce, F. Kolar, L. Bottolo, M. Mancini, N. Hubner, M. Pravenec, E. Petretto, C. MacRae, S.A. Cook, Wars2 is a determinant of angiogenesis, Nat. Commun. 7 (2016) 12061, https://doi.org/10.1038/ncomms12061.

[30] L.E. González-Serrano, L. Karim, F. Pierre, H. Schwenzer, A. Rötig, A. Munnich, M. Sissler, Three human aminoacyl-tRNA synthetases have distinct sub-mitochondrial localizations that are unaffected by disease-associated mutations, J. Biol. Chem. 293 (2018) 13604-13615, https://doi.org/10.1074/jbc.RA118.003400.

[31] S.H. Kevelam, F.C.C. Klouwer, J.M. Fock, G.S. Salomons, M. Bugiani, Absent thalami caused by a homozygous EARS2 mutation: expanding disease spectrum of LTBL, Neuropediatrics 47 (2016) 4.

[32] K. Danhauser, T.B. Haack, B. Alhaddad, M. Melcher, A. Seibt, T.M. Strom, T. Meitinger, D. Klee, E. Mayatepek, H. Prokisch, F. Distelmaier, EARS2 mutations cause fatal neonatal lactic acidosis, recurrent hypoglycemia and agenesis of corpus callosum, Metab. Brain Dis. 31 (2016) 717-721, https://doi.org/10.1007/s11011-016-9793-2.

[33] A. Ardissone, D. Tonduti, A. Legati, E. Lamantea, R. Barone, I. Dorboz, O. BoespflugTanguy, G. Nebbia, M. Maggioni, B. Garavaglia, I. Moroni, L. Farina, A. Pichiecchio, S. Orcesi, L. Chiapparini, D. Ghezzi, KARS-related diseases: progressive leukoencephalopathy with brainstem and spinal cord calcifications as new phenotype and a review of literature, Orphanet J. Rare Dis. 13 (2018) 45, https://doi.org/ 10.1186/s13023-018-0788-4.

[34] M. Itoh, H. Dai, S. Horike, J. Gonzalez, Y. Kitami, M. Meguro-Horike, I. Kuki, S. 
Shimakawa, H. Yoshinaga, Y. Ota, T. Okazaki, Y. Maegaki, S. Nabatame, S. Okazaki, H. Kawawaki, N. Ueno, Y. Goto, Y. Kato, Biallelic KARS pathogenic variants cause an early-onset progressive leukodystrophy, Brain 142 (2019) 560-573, https:// doi.org/10.1093/brain/awz001.

[35] M.S. van der Knaap, M. Bugiani, M.I. Mendes, L.G. Riley, D.E.C. Smith, J. RudingerThirion, M. Frugier, M. Breur, J. Crawford, J. van Gaalen, M. Schouten, M. Willems, Q. Waisfisz, F.T. Mau-Them, R.J. Rodenburg, R.J. Taft, B. Keren, J. Christodoulou, C. Depienne, C. Simons, G.S. Salomons, F. Mochel, Biallelic variants in LARS2 and KARS cause deafness and (ovario)leukodystrophy, Neurology (2019)https://doi. org/10.1212/WNL.0000000000007098.

[36] T. Linnankivi, N. Neupane, U. Richter, P. Isohanni, H. Tyynismaa, Splicing defect in mitochondrial Seryl-tRNA synthetase gene causes progressive spastic paresis instead of HUPRA syndrome: HUMAN MUTATION, Hum. Mutat. 37 (2016) 884-888, https://doi.org/10.1002/humu.23021.

[37] B.E. Theisen, A. Rumyantseva, J.S. Cohen, W.A. Alcaraz, D.N. Shinde, S. Tang, S. Srivastava, J. Pevsner, A. Trifunovic, A. Fatemi, Deficiency of WARS2, encoding mitochondrial tryptophanyl tRNA synthetase, causes severe infantile onset leukoencephalopathy, Am. J. Med. Genet. 173 (2017) 2505-2510, https://doi.org/ 10.1002/ajmg.a.38339.

[38] A. Ardissone, E. Lamantea, J. Quartararo, C. Dallabona, F. Carrara, I. Moroni, C. Donnini, B. Garavaglia, M. Zeviani, G. Uziel, A novel homozygous YARS2 mutation in two Italian siblings and a review of literature, in: J. Zschocke, M. Baumgartner, E. Morava, M. Patterson, S. Rahman, V. Peters (Eds.), JIMD Reports, Vol. 20, Springer, Berlin Heidelberg, Berlin, Heidelberg 2014, pp. 95-101, https://doi.org/10.1007/ 8904_2014_397.

[39] E.W. Sommerville, Y.S. Ng, C.L. Alston, C. Dallabona, M. Gilberti, L. He, C. Knowles, S.L. Chin, A.M. Schaefer, G. Falkous, D. Murdoch, C. Longman, M. de Visser, L.A. Bindoff, J.M. Rawles, J.C.S. Dean, R.K. Petty, M.E. Farrugia, T.B. Haack, H. Prokisch, R. McFarland, D.M. Turnbull, C. Donnini, R.W. Taylor, G.S. Gorman, Clinical features, molecular heterogeneity, and prognostic implications in YARS2-related mitochondrial myopathy, JAMA Neurol. (2017) 9. 


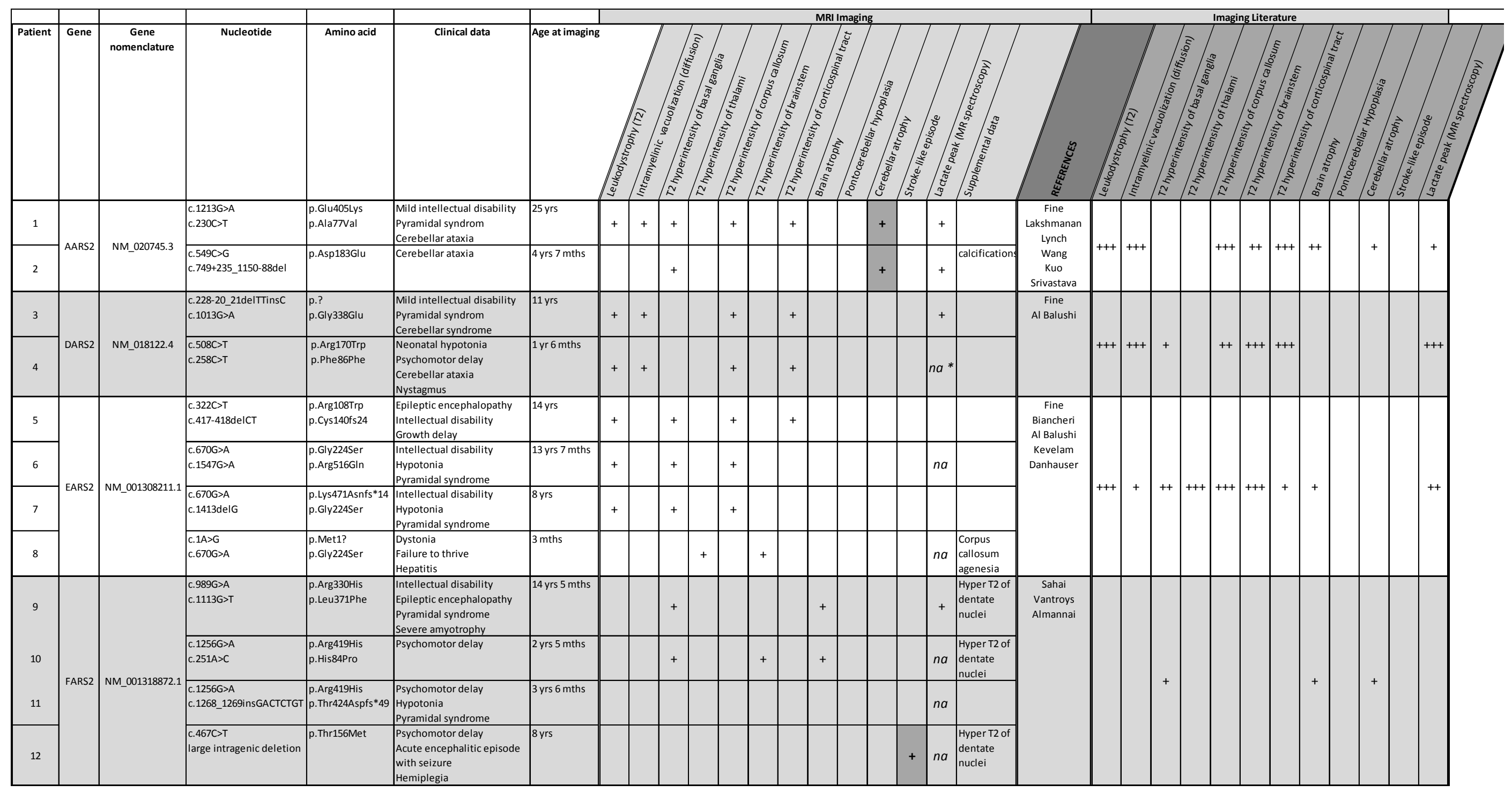




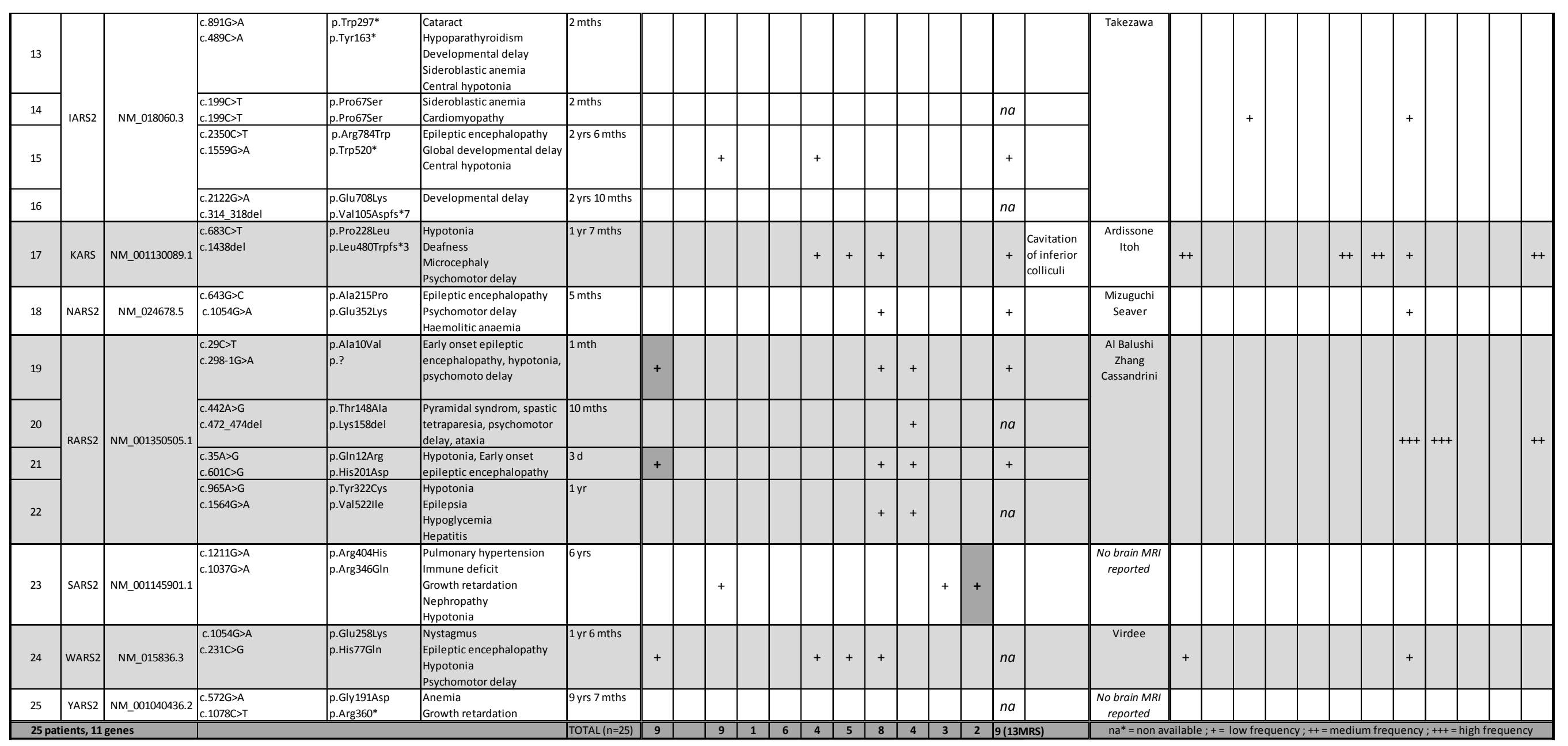

Table. Clinical, brain MRI and genetic features in 25 patients with ARS2 mutations compared to literature 
Table : Title

Clinical, brain MRI and genetic features in 25 patients with ARS2 mutations compared to li
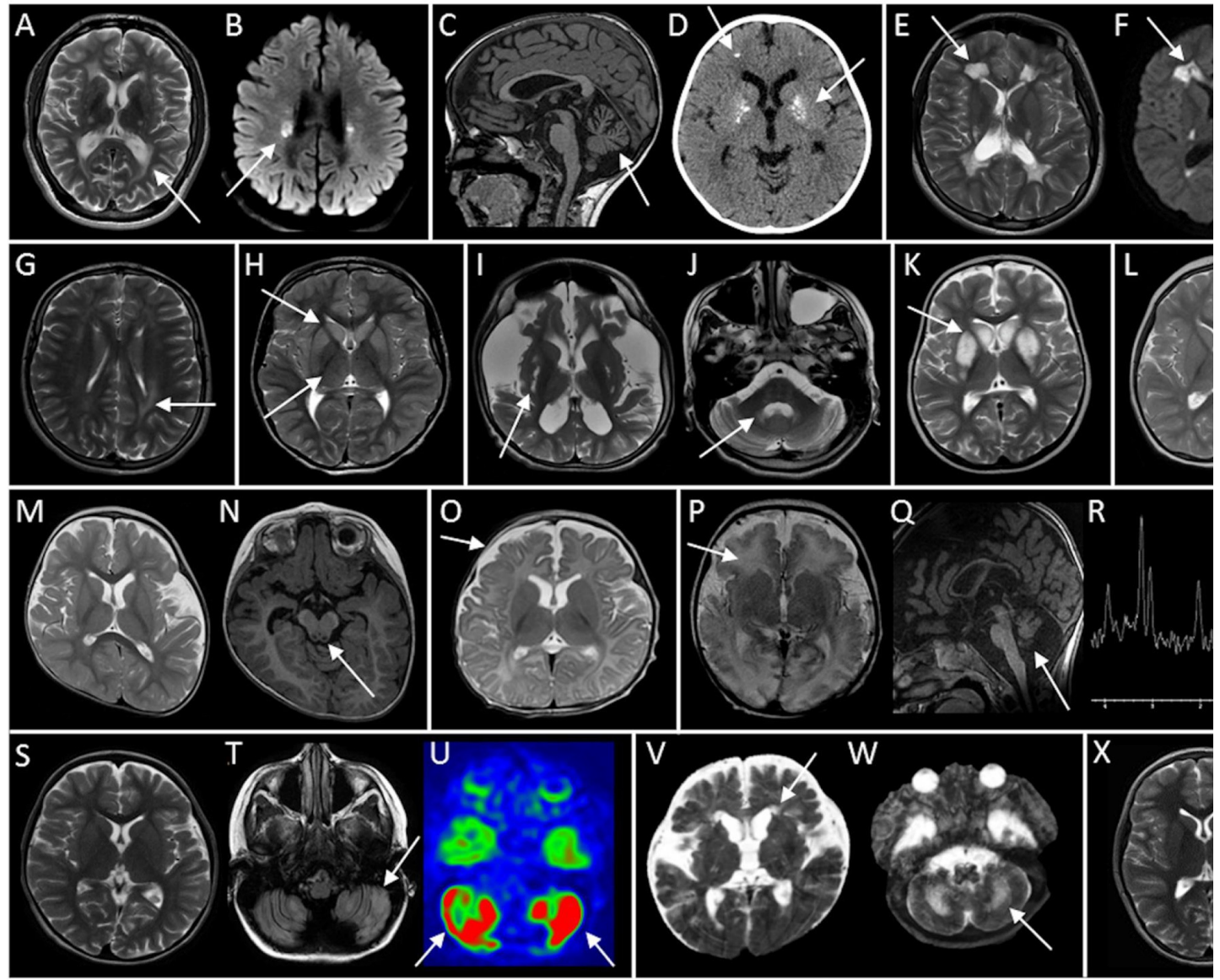

\section{Figure : Title and legend}

Illustration of brain MRI diversity in pathogenic ARS2 variants.

AARS2: [Figure panes] (A)-(D). [Patient] \#1: (A) periventricular leukodystrophy, T2-weight hyperintensities, diffusion-weighted image [DWI]. Apparent diffusion coefficient [ADC] map restrict frank cerebellar atrophy, sagittal T1-weighted image [T1WI]; (D) calcifications in basal ganglia and s matter, CT scan. DARS2: (E), (F). \#3: superimposable periventricular leukodystrophy in (E) T2WI restriction (not shown). EARS2: (G), (H). \#6: (G) leukodystrophy sparing periventricular rim, T2WI. \#: basal ganglia and absence of thalamic involvement, T2WI. FARS2: (I), (J). \#9: (I) severe diffuse brain in basal ganglia (Leigh syndrome) and (J) hyperintensities in dentate nuclei, T2WI. IARS2: (K), (L). \#1: basal ganglia (Leigh syndrome), T2WI. \#16: (L) no abnormality. KARS: (M), (N). \#17: (M) moderat T2WI; (N) cavitation of inferior colliculi, T1WI. NARS2: (0). \#18: moderate diffuse brain atrophy, T2I (P) early white matter changes with mild diffuse brain atrophy, T2WI; (Q) pontocerebellar hypor lactate peak, MRS. SARS2: (S)-(U). \#23: (S) no supratentorial anomaly, T2WI; (T) patchy cerebellar hy (U) spike in cerebellar cerebral blood flow with stroke-like lesion, arterial spin labelling. WAI periventricular leukodystrophy, T2WI; (W) brain stem and cerebellar white matter involvemen abnormality. 